\title{
Campanha de doação de sangue realizada por discentes de biomedicina: um relato de experiência
}

\author{
Blood donation campaign by biomedicine students: an experience report
}

\section{Campaña de donación de sangre realizada por estudiantes de biomedicina: un relato de experiencia}

João Batista Chaves Silva ${ }^{1}$, Kevellen Bezerra Ribeiro ${ }^{1}$, Larissy Christine Menezes Lisboa ${ }^{1}$, Kássia Helena Silva Leitão', Victória Kamilly Lima da Silva1, Tulio Vulcão Colares ${ }^{1}$, Lucas Yukio Emin Omura ${ }^{1}$, Paula Cristina Rodrigues Frade ${ }^{1,2 *}$.

\section{RESUMO}

Objetivo: Relatar a experiência vivenciada por discentes do curso de biomedicina no planejamento e na execução de uma campanha de doação de sangue. Relato de experiência: Trata-se de um estudo descritivo a respeito da vivência dos alunos sobre o desenvolvimento da campanha de doação de sangue "Vem ser doador" realizada entre janeiro e março de 2021. O objetivo foi aumentar o número de doadores, por meio da realização de uma campanha educativa para conscientizar a população a respeito da doação de sangue. Para isso, os alunos produziram materiais educativos e divulgaram nas redes sociais. Esses materiais continham uma breve explicação sobre a importância da doação de sangue e a segurança do processo. A doação de sangue coletiva ocorreu no dia 20 de fevereiro de $2021 \mathrm{em}$ um hemocentro, localizado no Estado do Pará, norte do Brasil. Considerações finais: A campanha contribuiu de forma significativa no aumento quantitativo de doações de sangue e na formação profissional dos discentes ao possibilitar a articulação do conhecimento e a integração ensino-comunidade.

Palavras-chave: Campanha de doação de sangue, Doador de sangue, Doação de sangue e redes sociais, Motivação para doação de sangue.

\begin{abstract}
Objective: Report the experience lived by Biomedicine students on planning and execution a blood donation campaign. Experience report: It is a descriptive study from the point of view of students about developing a blood donations campaign "Become a Donor" between January and March 2021. The aim was increase the admission for blood donation through educational campaign to create a high awareness about importance of blood donation. For that, the students developed educational materials and published at social media. These materials contained a brief education about the necessity of blood donation and the safety of the process. The blood donation happened in February 20th, 2021, at blood center, located in the state of Pará, north of Brazil. Final considerations: The campaign contributed significantly to increase the rate of admission for blood donations and improve the professional training of students by enabling knowledge articulation and teachingcommunity integration.
\end{abstract}

Keywords: Blood donation campaign, Blood donator, Blood donation and social media, Motivation for blood donation.

\section{RESUMEN}

Objetivo: Informar sobre la experiencia vivida por alumnos del curso de Biomedicina, reportando cómo se llevó a cabo la planificación y ejecución de una campaña de donación de sangre. Informe de experiencia: Se trata de un estudio descriptivo realizado en el período comprendido entre enero y marzo de 2021, desde el punto de vista de los alumnos del curso de Biomedicina en la creación de la campaña titulada "ven a ser donante". La acción tuvo como objetivo sensibilizar a la población sobre la donación de sangre con la finalidad de incentivar a todos aquellos que puedan ser donantes. La campaña se inició con la elaboración de

1 Universidade do Estado do Pará (UEPA), Belém - PA. *E-mail: paulacrfrade@gmail.com

2 Universidade Federal do Pará (UFPA), Belém - PA. 
materiales educativos sobre el proceso de donación, luego se llevó a cabo la difusión de estos materiales a través de las redes sociales y culminó con una donación colectiva de sangre realizada el 20 de febrero de 2021 en el centro de sangre, ubicado en el Estado del Pará, al norte de Brasil. Consideraciones finales: La campaña tuvo éxito, ya que contribuyó significativamente al incremento cuantitativo de las donaciones y en la formación profesional de los estudiantes al posibilitar la articulación de conocimientos y la integración enseñanza-comunidad.

Palabras clave: Campañas de donación de sangre, Donante de sangre, Donación de sangre y las redes sociales, Motivación para la donación de sangre.

\section{INTRODUÇÃO}

A hemoterapia atua no tratamento de patologias mediante a utilização de hemocomponentes e hemoderivados. A primeira transfusão sanguínea que teve êxito entre humanos foi realizada em 1818, o que possibilitou, em 1921, o surgimento do primeiro serviço especializado em transfusão na Inglaterra (LORDEIRO MAM, et al., 2017).

No Brasil, a hemoterapia teve início na década de quarenta, sendo marcada também por diversos avanços científicos que levaram ao surgimento dos primeiros bancos de sangue privados do país (JÚNIOR JBS, et al., 2015). Inicialmente, as doações de sangue, processo no qual um doador voluntário tem seu sangue coletado e armazenado para subsequente transfusão, eram remuneradas e não haviam políticas que fiscalizassem a qualidade do sangue utilizado, facilitando a transmissão de agentes infecciosos. Em 1964, com a criação da Comissão Nacional de Hemoterapia, foi estabelecida a Política Nacional do Sangue, que sofreu diversas alterações durante os anos, com o objetivo de garantir a qualidade dos serviços hemoterápicos. Atualmente, as doações são regidas pelo artigo 199 da Constituição Federal de 1988, que enfatiza a necessidade de a doação ser de cunho voluntário, além de priorizar o controle de qualidade (LORDEIRO MAM, et al., 2017).

Com relação ao ciclo do sangue, entende-se que os estágios se dão desde a captação de doadores de sangue, passando pela triagem clínica, coleta, triagem laboratorial, testes sorológicos e imunohematológicos, fracionamento dos hemocomponentes e, em última perspectiva, a transfusão dos componentes sanguíneos. O rigor do procedimento é de suma importância para assegurar que os riscos de reações adversas e a transmissão de patógenos sejam mínimos, tornando o processo mais efetivo, tanto para o doador quanto para o receptor do sangue (MINISTÉRIO DA SAÚDE, 2015).

Dessa forma, alguns critérios foram estabelecidos para garantir a seguridade na seleção de candidatos e no ato da doação, considerando-se a idade mínima de 16 anos (havendo a necessidade de os menores de idade estarem acompanhados por um responsável), e a idade máxima de 69 anos; a massa corpórea mínima deve ser de $50 \mathrm{~kg}$ e é importante que a aferição do pulso esteja entre 50 e 100 batimentos por minuto. Também são considerados durante a seleção dos doadores: a alimentação adequada, o comportamento de risco para Infecções Sexualmente Transmissíveis (IST) e ter dormido adequadamente na noite anterior ao ato (BRASIL, 2016).

Frente a demanda de produção hemoterápica no Brasil, as campanhas de incentivo à doação de sangue são importantes recursos utilizados pelos órgãos públicos e por outras instituições para dar visibilidade à necessidade desse ato e disseminar informações relevantes à população. Não só promover essas ações, mas também sensibilizar a população para a importância desse ato, é essencial para que ele se torne recorrente (STEPHANOU AT e MOREIRA MC, 2019).

O baixo número de campanhas indica que, socialmente, o ato de doar sangue não é visto como algo de muita importância, dificultando a captação de novos candidatos (MARTINS MH, 2016). De fato, em relação a frequência de doação de sangue, o doador de repetição ainda é o mais comum, equivalente a $43,3 \%$ do total de doações no ano de 2019, seguido das doações de primeira vez $(37,4 \%)$ e das doações esporádicas (19,3\%) (AGÊNCIA NACIONAL DE VIGILÂNCIA SANITÁRIA, 2021). Sob esse viés, percebe-se que as campanhas de doação de sangue que sensibilizam a população brasileira, mostram-se ações mais eficientes e necessárias para a captação de novos doadores (MINISTÉRIO DA SAÚDE, 2015). 
Pode-se citar como exemplo a campanha "Enfermagem está no sangue", de Silva NCDL, et al. (2021), que foi organizada por estudantes de enfermagem em Pernambuco no ano de 2018. Ela teve como objetivo a disseminação e a conscientização da população sobre a importância de doar sangue, para que dessa forma, $o$ ato se tornasse frequente. Apesar de não ter sido possível a quantificação dos doadores, os organizadores relataram que o evento foi de grande relevância para a comunidade, já que contribuiu com o aumento de doações, visibilidade para o tema e divulgação de informações relacionadas à doação.

Neste contexto, as campanhas de incentivo à doação de sangue são de suma importância, principalmente na atualidade em que a pandemia da doença do coronavirus 2019 (COVID-19), causada pelo novo coronavírus, o SARS-CoV-2, afetou diretamente o setor de produção hemoterápica (NGO A, et al., 2020). Dessa forma, medidas de incentivo à doação pela sensibilização se tornaram ainda mais necessárias, visto que, entre as principais ações tomadas para frear a propagação da COVID-19 pelo mundo, estão o distanciamento social e o bloqueio em massa de serviços não essenciais, que levou a redução a quantidade de doações de sangue, como consequência às restrições e ao receio populacional da exposição ao vírus. Logo, o número de doadores foi reduzido e os bancos de sangue passaram a apresentar carências no estoque de produtos sanguíneos, em contraposição, ocorreu o aumento da demanda de transfusões de hemocomponentes (SAHU KK, et al., 2020).

Assim, tendo em vista o cenário da pandemia de COVID-19 e a necessidade de ampliar o quantitativo de doações, discentes de biomedicina de uma universidade pública realizaram uma campanha de doação de sangue. Neste sentido, o presente trabalho visou relatar a experiência vivenciada pelos estudantes universitários de biomedicina na criação e na execução da campanha de doação de sangue intitulada "Vem ser doador".

\section{RELATO DE EXPERIÊNCIA}

A campanha foi planejada e executada por discentes e docente orientador do curso de biomedicina em parceria com o hemocentro de referência. A campanha intitulada "Vem ser doador" foi planejada no mês de janeiro e realizada, por meio de mídias sociais, nos meses de fevereiro e março de 2021 , sendo que a ação de doação de sangue coletiva ocorreu no dia 20 de fevereiro de 2021 em um hemocentro do Estado do Pará.

A campanha teve como intuito disseminar informações sobre a doação de sangue e mobilizar candidatos à doação para amenizar o problema da redução de doadores durante a pandemia da COVID-19. Assim, a partir da ideia inicial, os estudantes dividiram-se em grupos para a produção de materiais educativos, com linguagem acessível, baseados nos principais entraves frente à doação de sangue. A campanha teve como público-alvo todos aqueles que, segundo os critérios do Ministério da Saúde, estivessem aptos para a doação de sangue e pudessem estar presentes em Belém na data prevista do evento.

Inicialmente, no mês de janeiro de 2021, foi realizado o planejamento da campanha por meio de reuniões no formato virtual. Foram elegidas as seguintes diretrizes para nortear a campanha de doação de sangue: uso de fontes seguras para embasar a produção de conteúdo informativo, produção de materiais educativos com linguagem acessível, diversidade de conteúdo para evitar repetição de informações e definição de uma data para doação de sangue coletiva. Os meios selecionados para a divulgação dos conteúdos produzidos foram as redes sociais, já que sua grande abrangência no âmbito social facilita o alcance ao público-alvo, possui acesso livre e estão em consonância com as medidas de segurança adotadas durante a pandemia.

Foram desenvolvidos e divulgados infográficos que demonstravam o impacto da pandemia no número de doações em 2020, o perfil dos doadores nacionais, assim como o quantitativo do estoque sanguíneo regional, para justificar a necessidade de novos doadores. Somado a isso, no intuito de elucidar sobre a segurança na doação de sangue e o destino do sangue doado, foram elaboradas postagens, no formato de imagens ilustrativas sobre o ciclo do sangue, explicando com linguagem acessível as etapas desde a captação até a transfusão.

Adicionalmente, foram produzidas publicações de imagens com os requisitos para doar sangue, convites para a participação na doação de sangue coletiva e informações a respeito de dias, horários e locais de postos 
de coleta para doação na cidade de Belém, Pará. Todas as imagens e infográficos utilizados durante o desenvolvimento da campanha foram produzidos no site de ilustrações Canva. Ademais, produziu-se um podcast (adaptação moderna do rádio para as mídias digitais, tendo o áudio como ponto principal), no qual uma discente organizadora esclareceu questionamentos comuns sobre o processo de doação.

Posteriormente, foi realizada uma parceria com o centro acadêmico do curso de Biomedicina para a divulgação desses materiais educativos nas redes sociais Facebook e Instagram, publicados no intervalo entre a idealização e o fim da campanha, de modo que o público seguidor da página agregadora das publicações pudesse ter maior contato com o conteúdo. Além disso, os mesmos conteúdos foram compartilhados pelo Whatsapp dos apoiadores da campanha, e o Podcast foi divulgado em forma de vídeo em um canal no Youtube criado pelos discentes.

No dia 20 de fevereiro de 2021, no horário de 9 às 14 horas, ocorreu a culminância da campanha com a realização da doação de sangue coletiva. Com apoio dos profissionais do hemocentro, foi preparada uma área em frente à fundação para recepcionar os doadores convidados. A equipe organizadora estava padronizada com crachás de fácil reconhecimento, orientando as pessoas a retirarem senha, direcionaremse ao cadastramento na recepção e realizarem todos os procedimentos rotineiros do hemocentro.

Durante a recepção inicial, foi realizado o acolhimento, sendo enfatizado a importância do comparecimento do candidato à doação de sangue, e a elucidação de dúvidas acerca do ato de doar. Além disso, foram entregues números para a participação de sorteios de camisas confeccionadas pelos discentes com base na temática. Após a doação, os voluntários receberam uma mensagem de agradecimento e um chocolate, adicionalmente foram fornecidas orientações sobre uma possível próxima doação e a importância de realizarem este ato com frequência. Neste dia, o hemocentro contou com cerca de 400 doações de sangue. Por fim, as experiências de doar sangue e de realizar uma campanha de doação foram divulgadas nas redes sociais, como incentivo para ações futuras.

\section{DISCUSSÃO}

O impacto negativo da pandemia de COVID-19 nas doações de sangue fora ocasionado, tanto pelas medidas de isolamento social, quanto pelo aumento de receios e dúvidas em relação ao processo de doação, uma vez que muitos questionaram o quão seguro, de fato, seria submeter-se ao processo de coleta de sangue durante uma pandemia (SAHU KK, et al., 2020). Tais obstáculos enfrentados pelos hemocentros motivaram a elaboração da campanha "Vem ser doador", na qual as redes sociais foram os principais meios de disseminação de informações para a captação de doadores.

Desse modo, visto que indivíduos com menos de 30 anos são os principais consumidores das mídias sociais, estas se destacam como uma relevante estratégia a ser utilizada pelas campanhas de incentivo na procura por jovens doadores (SÜMNIG A, et al., 2018). No estudo de Silva MC, et al. (2021) houve a utilização das plataformas Instagram e Google Meet como forma de captação de doadores, por meio do diálogo e do esclarecimento de dúvidas, para o uso no projeto de extensão denominado "Programa sangue bom: Um olhar científico e humano para o ato de doar sangue", realizado no estado de Minas Gerais. Do mesmo modo, no presente estudo, foi realizada a consicientização e a mobilização para campanha de doação de sangue de forma virtual.

A utilização de mídias sociais foi um ponto chave na produção da campanha "Vem ser doador", realizada pelos discentes de biomedicina, com uso principalmente do Instagram, para difusão de imagens informativas de modo acessível aos usuários, e do Youtube para a divulgação do Podcast, que facilitou o aumento do seu alcance. Essas redes sociais, segundo Dupilar TC, et al. (2018), proporcionam um grande alcance do públicoalvo, facilitam o diálogo e a interação, além de ser uma forma efetiva de captação de doadores de sangue na atualidade.

A divulgação de informações a respeito da doação de sangue, por diferentes meios, é uma importante estratégia para ampliar o quantitativo de doações. Entre os diversos fatores que influenciam o baixo número de doadores de sangue, o medo, tanto em relação ao processo de doação quanto aos possíveis efeitos 
colaterais do mesmo, destaca-se como o principal deles (COELHO C e FARIA M, 2018). Em um estudo realizado em Cuba, o medo da punção foi a principal razão para a maioria dos indivíduos não doarem sangue (OCHOA-ORTEGA MR, et al., 2019). A falha na transmissão das informações mais essenciais também aparece como um grande empecilho na busca por novos doadores (PEREIRA JR, et al., 2016). Para superar tais barreiras, similar ao presente estudo, a ação de Lima HF, et al. (2020), mostrou-se necessária pela elaboração de materiais com foco no esclarecimento de dúvidas recorrentes e na desmistificação em relação a todo processo de doação, utilizando uma linguagem acessível.

Adicionalmente a produção e a divulgação de materiais educativos referentes à doação de sangue, a realização de uma doação de sangue coletiva foi essencial para mobilizar um maior número de doadores. Visto que é conhecida a importância de grupos ou pessoas de referência na influência do comportamento em relação ao incentivo à doação (PEREIRA JR, et al., 2019). Assim como, campanhas em grupo mobilizam de forma mais eficaz a população qualificada para a doação (PEREIRA JR, et al., 2016).

Nota-se, que a campanha descrita neste trabalho teve papel fundamental na formação dos envolvidos, uma vez que além de proporcionar a difusão de uma ideia central, a doação de sangue, e promover o trabalho em equipe, também possibilitou a realização de um estudo prático, no que se refere às pesquisas e aplicação de conteúdos teóricos, adaptado ao quadro pandêmico do período em questão. Aplicar na prática as teorias aprendidas, assim como estimular o desenvolvimento da ação em conjunto, são essenciais para a formação profissional (CARVALHO VL, et al., 2017).

Outras campanhas de doação de sangue organizadas por discentes de cursos da saúde também ocorreram de forma exitosa (LOPES J, 2016; SILVA NCDL, et al., 2021). Nessas campanhas, os discentes relataram o enriquecimento da vida acadêmica, por oportunizar o repasse de informações aprendidas na universidade para a população e a formação de indivíduos mais empáticos e engajados com o bem-estar social (LOPES J, 2016; SILVA NCDL, et al., 2021). Dessa forma, o planejamento e a execução da campanha relatada neste trabalho foi uma experiência engrandecedora para a aquisição de habilidades e competências requisitadas para a prática profissional.

Portanto, a campanha de doação de sangue "Vem ser doador" contou com a produção de materiais educativos, a divulgação destes materiais em redes sociais e a realização de uma doação de sangue coletiva, que contribuiu para o aumento do estoque de bolsas de sangue ao atrair novos e antigos doadores. Além disso, a campanha proporcionou uma experiência agregadora que cooperou para o crescimento e desenvolvimento pessoal e profissional dos discentes. Por fim, este relato fornece informações que podem auxiliar na organização de campanhas de doações de sangue futuras.

\section{REFERÊNCIAS}

1. AGÊNCIA NACIONAL DE VIGILÂNCIA SANITÁRIA (ANVISA). $8^{\circ}$ Boletim de produção hemoterápica no Brasil. 2021. Disponível https://app.powerbi.com/view?r=eyJrljoiOTVhYzk3MzctYzI4MS00YWYOLWJiM2ItMzRmZTY0ZTM4NGEzliwidCI6Iml 2N2FmMjNmLWMzZjMtNGQzNS04MGM3LWI3MDg1ZjVIZGQ4MSJ9. Acessado em: 25 de junho de 2021.

2. BRASIL. Portaria ${ }^{\circ}{ }^{158}$, de 4 de Fevereiro de 2016. 2016. Disponível em: https://www.in.gov.br/web/dou/-/portaria-n158-de-4-de-fevereiro-de-2016-22301274. Acessado em: 04 de julho de 2021.

3. CARVALHO VL, et al. Competências para promoção da saúde em formandos dos cursos da área da saúde. Revista de Enfermagem UFPE online, 2017; 11(8): 3269-3278.

4. COELHO C, FARIA M. Intenções podem salvar vidas? Motivações e dificuldades de potenciais doadores de sangue à luz do marketing social. Revista Ciências Sociais em Perspectiva, 2018; 17(33): 157-178.

5. DUPILAR TC, et al. Captação de doadores de sangue: da era científica mundial à era da informação digital. Serviço Social e Saúde, 2018; 17(1): 95-126.

6. JÚNIOR JBS, et al. Regulação de sangue no Brasil: contextualização para o aperfeiçoamento. Revista Panam Salud Publica, 2015; 38(4): 333-338.

7. LIMA HF, et al. Educação em saúde sobre doação de sangue: relato de uma experiência com crianças e adolescentes. Research, Society and Development, 2018; 9(9): e780997941-e780997941.

8. LOPES J, et al. Segurança do paciente e doação de sangue: a experiência de acadêmicos de enfermagem. Salão do Conhecimento, 2016. 
9. LORDEIRO MAM, et al. Evolução da história de doação de sangue no Brasil dentro do âmbito do SUS. Revista Rede de Cuidados em Saúde, 2017; 11(3).

10. MARTINS MH, et al. A importância do banco de sangue no cenário hemoterápico. Revista Eletrônica Unifia, 2016.

11. MINISTÉRIO DA SAÚDE. Secretaria de Atenção à Saúde. Departamento de Atenção Especializada e Temática. Manual de orientações para a promoção da doação voluntária de sangue. Brasil, 2015. Disponível em: https://bvsms.saude.gov.br/bvs/publicacoes/manual_orientacoes_promocao_doacao_voluntaria_sangue.pdf. Acessado em: 04 de julho de 2021

12. NGO A, et al. Blood banking and transfusion medicine challenges during the COVID-19 pandemic. Clinics in Laboratory Medicine, 2020; 40(4): 587-601.

13. OCHOA-ORTEGA MR, et al. Resultados da aplicação de um programa educativo sobre doação de sangue. Revista Camagüey Medical Archive, 2019; 23(2): 223-232.

14. PEREIRA JR, et al. Doar ou não doar, eis a questão: uma análise dos fatores críticos da doação de sangue. Ciência \& Saúde Coletiva, 2016; 21: 2475-2484.

15. PEREIRA JR, et al. Entre o bem-estar social e o poder público: uma análise das estratégias de marketing social em prol da doação sanguínea. Revista Brasileira de Marketing, 2019; 18(1): 73-85.

16. SAHU KK, et al. "Because Every Drop Counts": Blood donation during the COVID-19 Pandemic. Transfusion Clinique et Biologique: Journal de La Societe Francaise de Transfusion Sanguine, 2020; 27(3): 105-108.

17. SILVA NCDL, et al. Doação de sangue: experiência exitosa na campanha enfermagem está no sangue. Revista Eletrônica Acervo Enfermagem, 2021; 8: e4865.

18. SILVA MC, et al. Programa "Sangue Bom": Estratégias de mobilização para captação de doadores de sangue durante a pandemia da covid-19. Expressa Extensão, 2021; 26(1): 318-327.

19. STEPHANOU AT, MOREIRA MC. Blood donors' perception of incentive campaigns. Paidéia (Ribeirão Preto), 2019; 29.

20. SÜMNIG A, et al. The role of social media for blood donor motivation and recruitment. Transfusion, 2018; 58(10): 22572259. 